\title{
Modulation of the pentose phosphate pathway alters phase I metabolism of testosterone and dextromethorphan in HepG2 cells
}

\author{
Wen-jing XIAO, Ting MA, Chun GE, Wen-juan XIA, Yong MAO, Run-bin SUN, Xiao-yi YU, Ji-ye AA* , Guang-ji WANG \\ Key Laboratory of Drug Metabolism and Pharmacokinetics, Jiangsu Key Laboratory of Drug Design and Optimization, State Key \\ Laboratory of Natural Medicines, China Pharmaceutical University, Nanjing 210009, China
}

\begin{abstract}
Aim: The pentose phosphate pathway (PPP) is involved in the activity of glucose-6-phosphate dehydrogenase (G6PD) and generation of NADPH, which plays a key role in drug metabolism. The aim of this study was to investigate the effects of modulation of the PPP on drug metabolism capacity in vitro.

Methods: A pair of hepatic cell lines, ie the cancerous HepG2 cells and normal L02 cells, was used. The expression of CYP450 enzymes, p53 and G6PD in the cells were analyzed. The metabolism of testosterone (TEST, $10 \mu \mathrm{mol} / \mathrm{L}$ ) and dextromethorphan (DEM, $1 \mu \mathrm{mol} / \mathrm{L}$ ), the two typical substrates for CYP3A4 and CYP2D6, in the cells was examined in the presence of different agents.

Results: Both the expression and metabolic activities of CYP3A4 and CYP2D6 were considerably higher in HepG2 cells than in LO2 cells. The metabolism of TEST and DEM in HepG2 cells was dose-dependently inhibited by the specific CYP3A4 inhibitor ketoconazole and CYP2D6 inhibitor quinidine. Addition of the p53 inhibitor cyclic PFT- $\alpha$ (5, $25 \mu \mathrm{mol} / \mathrm{L})$ in HepG2 cells dose-dependently enhanced the metabolism of DEM and TEST, whereas addition of the p53 activator NSC 66811 (3, 10, $25 \mu \mathrm{mol} / \mathrm{L})$ dose-dependently inhibited the metabolism. Furthermore, addition of the G6PD inhibitor 6 -aminonicotinamide $(5,15 \mu \mathrm{mol} / \mathrm{L})$ in HepG2 cells dose-dependently inhibited the metabolism of DEM and TEST, whereas addition of the PPP activity stimulator menadione $(1,5,15 \mu \mathrm{mol} / \mathrm{L}) \mathrm{dose}-$ dependently enhanced the metabolism.

Conclusion: Modulation of p53 and the PPP alters the metabolism of DEM and TEST, suggesting that the metabolic flux pattern of PPP may be closely involved in drug metabolism and the individual variance.
\end{abstract}

Keywords: drug metabolism; HepG2 cells; pentose phosphate pathway; G6PD; p53; CYP; testosterone; dextromethorphan; ketoconazole; quinidine; cyclic PFT- $\alpha$; NSC 66811; 6-aminonicotinamide; menadione

Acta Pharmacologica Sinica (2015) 36: 259-267; doi: 10.1038/aps.2014.137; published online 26 Jan 2015

\section{Introduction}

Individual variation greatly challenges the personalized therapy of various drugs in the clinic. Although pharmacogenetic polymorphisms play an important role in a drug's clinical therapeutic failure and side effects ${ }^{[1,2]}$, polymorphisms only partially contribute to the individual variance of drug metabolism. Apart from the polymorphisms of cytochrome P450 (CYP), the effectiveness of a drug varies according to a person's genetic variation, lifestyle, dietary preferences, and environment. However, the difficulty of quantifying multiple confounding factors, which has been a challenge for individualized drug therapy, and other intrinsic factors have made it

\footnotetext{
\# The first three authors contributed equally to this work.

* To whom correspondence should be addressed.

E-mail jiyea@cpu.edu.cn

Received 2014-08-26 Accepted 2014-10-21
}

difficult to determine the factors that contribute to the individual variance of drug metabolism.

A person's response to a drug or chemical can be manifested in many ways, such as protein expression, enzyme activity and function, and fundamental metabolism. As the end products of systemic function and various metabolic pathways, the small molecules inside of the body are reflective of the metabolic pattern and individual response. Hence, metabolomic analysis of the baseline endogenous metabolites provides a possible approach for associating individual variances with the in vivo fate of a drug. Pharmacometabolomic modeling is therefore considered a potentially effective method in evaluating individual variances to broader medical treatments, which was defined as 'the prediction of the outcome (for example, efficacy or toxicity) of a drug or xenobiotic intervention in an individual based on a mathematical model of pre-intervention metabolite signatures ${ }^{[3]}$. Some pioneering work in pharmaco- 
metabolomics has suggested its usefulness in correlating the individual baseline of the endogenous metabolism with the method of drug disposition involved in toxicity ${ }^{[4,5]}$.

Although pharmacometabolomic studies indicate the usefulness in characterizing metabolic patterns, little is understood about the underlying association. As a bridge between endogenous and xenobiotic metabolism, the pentose phosphate pathway (PPP) is involved in the activity of glucose-6-phosphate dehydrogenase (G6PD) and generation of reduced nicotinamide adenine dinucleotide phosphate (NADPH), which plays a key role in drug metabolism ${ }^{[6]}$. The PPP is a ubiquitous glucose metabolic pathway in animals, plants and microorganisms that has crucially important physiological functions. In mammals, the PPP exists exclusively in the cytoplasm, and it is most active in the liver, mammary gland and adrenal cortex in humans ${ }^{[7]}$. Of the three primary pathways that the body uses to create molecules with reducing power, the PPP is the most critical, accounting for approximately $60 \%$ of NADPH production in humans; G6PD plays a key role in the PPP activity ${ }^{[8]}$.

Cancer cells are characterized by distinctive metabolic reprogramming ${ }^{[9,10]}$. Most cancer cells predominantly produce energy via a high rate of glycolysis followed by lactic acid fermentation in the cytosol, rather than by a comparatively low rate of glycolysis followed by pyruvate oxidation through the tricarboxylic acid cycle in mitochondria as in normal cells; this process in cancer cells is known as the Warburg effect ${ }^{[11,12]}$. Recently, scientists reported that p53 plays an important role in modulating the PPP by acting on G6PD, which is the limiting rate enzyme for the PPP. Normally, G6PD activity is inhibited by p53 such that the PPP is well controlled, and glycolysis and the tricarboxylic acid cycle generate sufficient energy for cell growth. However, the PPP can become highly elevated in response to either a mutation in or absence of p53 in cancer cells ${ }^{[13]}$. The reduced function of $\mathrm{p} 53$ in cancer cells can alter the metabolic capacity of drugs ${ }^{[14]}$. Additionally, recent studies on G6PD have suggested that modulation of G6PD significantly alters the intracellular metabolome/metabolites and proteome/proteins that are involved in the generation of NADPH and drug metabolism, indicating the potential effect of the PPP on drug metabolism ${ }^{[15,16]}$. Unfortunately, the direct modulation of the PPP on the typical substrates of CYP enzymes has not been studied, even though CYP expression has been documented ${ }^{[17-19]}$.

To evaluate whether the efficiency of the drug metabolism depends on the PPP and p53, two metabolic substrates of CYP450 enzymes, ie, dextromethorphan (DEM) and testosterone (TEST), which are the typical substrates of CYP2D6 and CYP3A4, respectively, were used. A pair of hepatic cell lines, ie, the cancerous HepG2 cells and normal L02 cells, which were derived from the hepatocellular carcinoma tissue of a 15-year-old Caucasian American male and a non-tumor human liver, respectively, was used in this study. By using classic agonists and inhibitors, the modulatory effects of the PPP and p53 on the two substrates metabolism was assessed. Ultimately, our goal was to establish the relationship between the endogenous metabolic baseline of individuals and the individual variation of drug metabolism, which could bridge the endogenous metabolism and xenobiotic metabolism.

\section{Materials and methods Chemicals}

Dextromethorphan hydrobromide, testosterone, orphenadrine, quinidine, ketoconazole, 6-aminonicotinamide (6-AN) and menadione were of analytical grade and purchased from Sigma-Aldrich (St Louis, MO, USA). NSC 66811 and cyclic PFT-a were purchased from Crescent Chemical Co, Inc (New York, USA). Orphenadrine was used as an internal standard (IS). Dulbecco's Modified Eagle's Medium was purchased from Invitrogen Co (Carlsbad, CA, USA); fetal bovine serum was purchased from Atlanta Biologicals Inc (Flowery Branch, GA, USA); and penicillin and streptomycin was purchased from Mediatech Inc (Manassas, VA, USA). The enhanced BCA protein assay kit was purchased from Beyotime Institute of Biotechnology (Haimen, China) and the Glucose-6-Phosphate Dehydrogenase activity assay kit (GMS70013.1 v.A) was purchased from Genmed Scientifics Inc (Wilmington, DE, USA). Acetonitrile (Merck, Darmstadt, Germany) was of highpressure liquid chromatography (HPLC) grade. Acetic ether (chromatographic grade) was purchased from Pierce Chemical Company (Rockford, IL, USA).

\section{Cell culture}

HepG2 cells and L02 cells obtained from the American Type Culture Collection (Manassas, VA) were cultured in Dulbecco's Modified Eagle's Medium supplemented with $10 \%$ fetal calf serum, $100 \mathrm{U} / \mathrm{mL}$ penicillin, $100 \mathrm{ng} / \mathrm{mL}$ streptomycin, $4 \mathrm{mmol} / \mathrm{L}$ glutamine, and 1\% non-essential amino acids (all purchased from Gibco) and then incubated in a humidified 5\% $\mathrm{CO}_{2}$ atmosphere at $37^{\circ} \mathrm{C}$. The medium was refreshed every two days. Cells were passaged upon reaching approximately $80 \%$ confluence. All of the cells used in this study were between passage 10 and 20. A suspension of monolayer-cultured cells was seeded at a density of 4000 cells/well in either 6 or 12-well plates. The protein concentration in the cells was determined with the Enhanced BCA Protein Assay Kit.

\section{RNA isolation and qRT-PCR (quantitative real-time PCR)}

Total RNA was obtained with the TRIzol method. Total RNA $(0.5 \mu \mathrm{g} / \mathrm{mL})$ was reverse-transcribed into cDNA, and qRT-PCR was carried out using the CFX96 real-time RT-PCR detection system with a C1000 thermal cycler (Bio-Rad, USA), according to the manufacturer's instructions, to quantify the CYP1A2, 2C9, 2C19, 2D6, 3A4, p53, G6PD, and $\beta$-actin levels. The RT-PCR primers that were used are shown in Table 1. PCR amplification included 1 cycle of denaturation at $95^{\circ} \mathrm{C}$ for either 3 min (CYPs and G6PD) or $30 \mathrm{~s}$ (p53 and $\beta$-actin), which was followed by 40 cycles of denaturation at $95^{\circ} \mathrm{C}$ for $30 \mathrm{~s}$, annealing (at the temperatures indicated in Table 1) for $30 \mathrm{~s}$, and synthesis at $72{ }^{\circ} \mathrm{C}$ for $30 \mathrm{~s}$.

\section{Western blot assay}

The cellular protein concentration was measured using the 
Table 1. Primers and annealing temperatures used for qRT-PCR.

\begin{tabular}{llc}
\hline Gene & \multicolumn{1}{c}{$\begin{array}{c}\text { Forward primer/Reverse primer } \\
\left(5^{\prime}-3^{\prime}\right)\end{array}$} & $\begin{array}{c}\text { Annealing temperature } \\
\left({ }^{\circ} \mathrm{C}\right)\end{array}$ \\
\hline CYP1A2 & AGGGCTTGTTATGGCAGTG/CTTCGTAAACCAGTGGCAGG & 56 \\
CYP2C9 & TACAGATAGGTATTAAGGACAT/TCACTGCTTCATATCCAT & 56 \\
CYP2C19 & AAATCCTTACCAATCTCTC/TTCCTTCACCACTTCATA & 56 \\
CYP2D6 & TGGCAGAGATGGAGAAGG/CGGCAGAGACAGGTCAG & 56 \\
CYP3A4 & CAATGGACTGCATAAATAACCG/GAGCCAAATCTACCTCCTCACA & 56 \\
P53 & CCATGAGCGCTGCTCAGAT/CAACCTCAGGCGGCTCATA & 60 \\
B-actin & GGCAACAGATACAAGAACATGAACCCTCATACTGGAACCCACT & 60 \\
\hline
\end{tabular}

BCA assay. Equal protein levels $(36 \mu \mathrm{g})$ were separated on a $10 \%$ SDS-polyacrylamide gel and transferred onto polyvinylidene difluoride (PVDF) membranes. The membranes were blocked with $5 \%$ nonfat milk in TBST (Tris-buffered saline containing $0.05 \%$ Tween 20 ) at $37^{\circ} \mathrm{C}$ for $1 \mathrm{~h}$ and then incubated with diluted primary antibodies [1:200 for p53 and G6PD (Santa Cruz Biotechnology, USA) and 1:2000 for GAPDH (Bioworld, USA)] overnight at $4{ }^{\circ} \mathrm{C}$. After washing, the membranes were incubated with the appropriate secondary antibody for $1 \mathrm{~h}$ at $37^{\circ} \mathrm{C}$. The protein levels were determined using image processing, analyzed with digitalized software (Quantity One, BIO-RAD, USA), and normalized to the reference band GAPDH.

\section{G6PD activity assay}

In the oxidative phase of the PPP, glucose 6-phosphate (G6P) is converted into 6-phosphoglucono- $\delta$-lactone by G6PD, which generates NADPH with a 1:1 stoichiometry. G6PD activity was then examined by measuring the conversion rate of $\mathrm{NADP}^{+}$to NADPH in the presence of G6P. In detail, G6PD activity was determined as described in the Glucose6-Phosphate Dehydrogenase activity assay kit (GMS70013.1 v.A); cell lysates were added to the reaction buffer containing Reagents C\&D. After incubation at $25^{\circ} \mathrm{C}$ for 2 min, Reagent $\mathrm{E}$ was mixed with the reaction mixture, and the absorbance was measured at $340 \mathrm{~nm}$. The enzyme activities were normalized based on the protein concentration. The data are expressed in the enzymatic activity unit, which is defined as micromoles of G6P converted into 6-phosphoglucono- $\delta$-lactone $\left(25^{\circ} \mathrm{C}, \mathrm{pH}\right.$ 7.4) per minute based on this kit.

\section{Determination of xenobiotic metabolizing ability of HepG2 cells}

HepG2 and L02 cells were incubated with specified drugs in DMEM without serum under the same conditions. Approximately $200 \mu \mathrm{L}$ of medium from each culture dish was transferred into 1.5-mL Eppendorf tubes after the drug administration period and stored in a freezer $\left(-20^{\circ} \mathrm{C}\right)$ before extraction. The remaining drug-containing medium was discarded, and the cells were washed three times using phosphate buffered solution and lysed by three freeze-thaw cycles. Approximately $1000 \mu \mathrm{L}$ of acetic ether (containing $0.1 \mathrm{ng} / \mathrm{mL}$ IS) was added to each tube, vigorously vortexed for $5 \mathrm{~min}$, and cen trifuged at $18000 \mathrm{r} / \mathrm{min}$ for $10 \mathrm{~min}$ at $4^{\circ} \mathrm{C}$. To ensure that the same levels of medium extracts were analyzed, the supernatants were quantitatively transferred (approximately $900 \mu \mathrm{L}$ ) to another tube and evaporated to dryness in an SPD2010-230 SpeedVac Concentrator (Thermo Savant, Waltham, MA, USA) at room temperature. After the sample was redissolved in $100 \mu \mathrm{L}$ of acetonitrile and centrifuged at $18000 \mathrm{r} / \mathrm{min}$ at $4^{\circ} \mathrm{C}$ for $10 \mathrm{~min}, 70 \mu \mathrm{L}$ of the supernatant was used for LC-MS/MS analysis.

\section{LC-MS/MS analysis}

An LC system (LC-20A, SHIMADZU, Japan) consisting of an autosampler, binary pump, and column oven was used for separating the samples. The separation was performed on a Luna C18(2) column (150 mm×2.0 mm, $5 \mu \mathrm{m}, 100 \AA$ A Phenomenex, USA). The mobile phase consisted of $2 \mathrm{mmol} / \mathrm{L}$ ammonium acetate and $0.01 \%$ acetic acid in water (A) and acetonitrile (B). A gradient elution was used at a flow rate of $0.5 \mathrm{~mL} / \mathrm{min}$. The initial buffer composition was $2 \% \mathrm{~B}$. The gradient program was as follows: $0-0.5 \mathrm{~min}, 2 \% \mathrm{~B} ; 0.5-4.5$ min, 2\%-45\% B; 4.5-6.5 min, 45\%-60\% B; 6.5-6.8 min, 60\%$80 \% \mathrm{~B} ; 6.8-7.2 \mathrm{~min}, 80 \%-80 \% \mathrm{~B} ; 7.2-7.5 \mathrm{~min}, 80 \%-2 \% \mathrm{~B}$; and $7.5-10 \mathrm{~min}, 2 \%-2 \% \mathrm{~B}$. The column was maintained at $40^{\circ} \mathrm{C}$. The HPLC system was coupled to an API 4000 triple quadrupole mass spectrometer (Applied Biosystems, Foster City, CA, USA) with a turbo ion spray source. Electrospray ionization (ESI) was performed in the positive ion mode with nitrogen as the ion source and curtain gas with optimal values set at 65/70 and $30 \mathrm{Arb}$, respectively. The turbo gas temperature was set to $500^{\circ} \mathrm{C}$, and the IonSpray voltage was adjusted to $5500 \mathrm{~V}$. Multiple reaction monitoring (MRM) was performed using nitrogen as the collision gas with a dwell time of $50 \mathrm{~ms}$ for each transition. Table 2 shows the MRM transitions and MS fragmentation parameters for the primary analytes. Automatic peak detection and calculation of the peak area of specific compounds and IS were analyzed using the Analyte 1.5.1 software.

\section{Statistical analysis}

All results in the text and figures are represented as the 
Table 2. MRM transitions and MS fragmentation parameters for the primary analytes.

\begin{tabular}{|c|c|c|}
\hline Analytes & $\begin{array}{c}\text { Q1/Q3 } \\
(m / z, \mathrm{Da})\end{array}$ & $\begin{array}{c}\mathrm{DP} / \mathrm{CE} \\
(\mathrm{V})\end{array}$ \\
\hline Testosterone (TEST) & 289.3/97.4 & $160 / 36$ \\
\hline 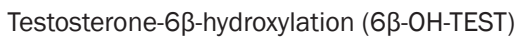 & $305.0 / 269.0$ & $60 / 21$ \\
\hline Dextromethorphan (DEM) & $272.3 / 213.2$ & $200 / 38$ \\
\hline Dextrorphan (DEX) & $258.5 / 157.0$ & $120 / 52$ \\
\hline Orphenadrine (IS) & $270.0 / 181.0$ & $40 / 15$ \\
\hline
\end{tabular}

mean \pm SEM. The results were evaluated with the Student's $t$ test. A value of $P<0.05$ was considered statistically significant.

\section{Results}

\section{mRNA Expression of CYPs in HepG2 and L02 cells}

The CYP1A2, 2C9, 2C19, 2D6, and 3A4 transcripts were all detectable in both HepG2 and L02 cells. The Ct values indicated a distinct, higher expression level of CYP2D6 and 3A4, whereas the CYP1A2, 2C9, and 2C19 expression levels were lower in both HepG2 and L02 cells. In general, the mRNA levels of all tested CYP enzymes were higher in HepG2 cells (Figure 1A). Specifically, the CYP1A2 levels were 4-fold higher in HepG2 cells, and the CYP2C9 and CYP2C19 levels were 2-fold higher in HepG2 cells. Additionally, the CYP2D6 and CYP3A4 expression levels were more than 5-fold higher in HepG2 cells compared to L02 cells.

\section{Drug metabolism in HepG2 cells}

Pilot studies showed that the substrates DEM and TEST, as well as their respective metabolites DEX and $6 \beta-O H-T E S T$, could be abundantly detected after either 12 or $24 \mathrm{~h}$ of treatment in HepG2 cells (see LC-MS/MS spectrogram in Supplementary Information, Figure S1). The DEX and 6 $\beta-O H-T E S T$ production after a 12-h incubation was lower than that after a 24-h incubation, but there was a similar difference between HepG2 and L02 cells at both time points. The measurement of the DEM levels and its CYP2D6 metabolite (DEX) showed that DEM was significantly metabolized into DEX in HepG2 cells, whereas less DEX was generated in L02 cells (less than $2 \%$ of the level in HepG2 cells) (Figure 1B), indicating that HepG2 cells have more CYP2D6 activity. Analysis of TEST and its CYP3A4 metabolite $6 \beta-\mathrm{OH}-\mathrm{TEST}$ revealed that TEST could be efficiently metabolized into $6 \beta-\mathrm{OH}$-TEST in HepG2 cells, whereas there was a lower production of $6 \beta-\mathrm{OH}-\mathrm{TEST}$ in L02 cells (approximately 11\% of the level in HepG2 cells) (Figure 1B), indicating that HepG2 cells also have more CYP3A4 activity. Taken together, the CYP2D6 and CYP3A4 activity levels in HepG2 cells were higher than in L02 cells (Figure 1C), which is consistent with the differences in the mRNA levels in these cell lines.

\section{Effects of specific inhibitors on the metabolic capacity of HepG2 cells}

To evaluate the modulation of the metabolic activity of CYPs in HepG2 cells, specific inhibitors were added to the in vitro system. DEM and TEST were added to HepG2 cells in the
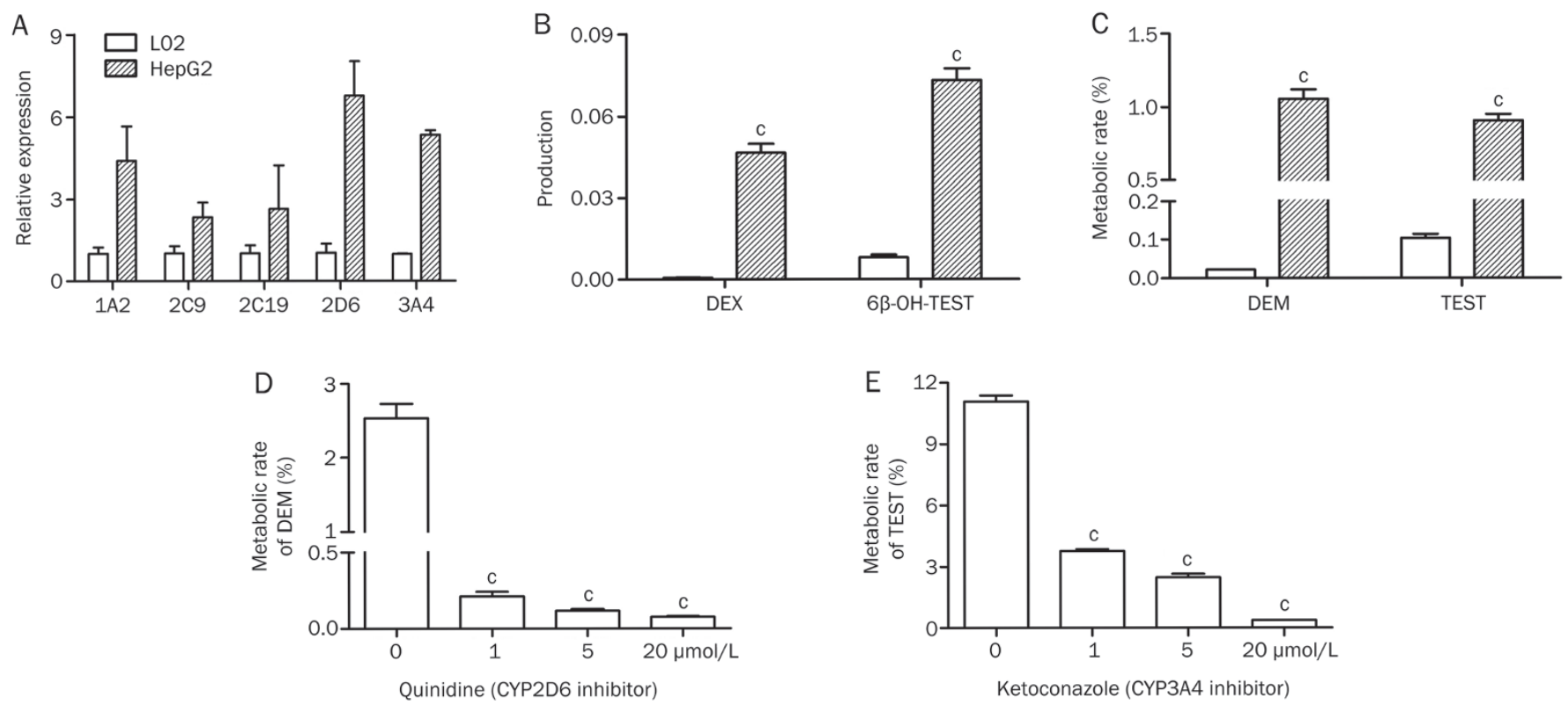

Figure 1. mRNA expression of CYPs and the metabolic capacity of HepG2 cells and L02 cells.(A) The mRNA expression levels of CYP 1A2, 2C9, 2C19, 2D6, and 3A4 in HepG2 and L02 cells. The results are presented as the mRNA expression levels relative to $\beta$-actin. HepG2/L02>2, $P<0.05, n=6$. (B) DEX and $6 \beta \mathrm{OH}-\mathrm{TEST}$ production (normalized by cell amount) in HepG2 and L02 cells after treatment with either DEM (1 $\mu \mathrm{mol} / \mathrm{L})$ or TEST (10 $\mu \mathrm{mol} / \mathrm{L})$ for $24 \mathrm{~h}$. (C) The metabolic rate (\%, metabolite/substrate) of DEM and TEST (24 h). (D) Inhibitory effects of quinidine on CYP2D6 activity in HepG2 cells. Cells were incubated for $24 \mathrm{~h}$ with $1 \mu \mathrm{mol} / \mathrm{L}$ of DEM in the presence of quinidine $(0,1,5$, or $20 \mu \mathrm{mol} / \mathrm{L})$. (E) Inhibitory effects of ketoconazole on CYP3A4 activity in HepG2 cells (24 h). ${ }^{\mathrm{b}} P<0.05,{ }^{\mathrm{c}} \mathrm{P}<0.01$ vs L02 cells (A, B, and C) or vs Ctr (D and E). 
presence of either quinidine (QND, a CYP2D6 inhibitor) or ketoconazole (KET, a CYP3A4 inhibitor), respectively. The DEM, DEX, TEST, and $6 \beta-\mathrm{OH}-\mathrm{TEST}$ concentrations in the culture media were measured after $24-\mathrm{h}$ incubation. The QND significantly inhibited the metabolism of DEM $(P<0.01)$ in a dose-dependent manner (Figure 1D). The addition of QND at 1,5 , and $20 \mu \mathrm{mol} / \mathrm{L}$ resulted in 12.1-, 21.7-, and 32.9-fold reductions in the metabolism of DEM, indicating that the in vitro system with HepG2 cells is appropriate for assessing the metabolic pathway involved with CYP2D6. Similarly, KET significantly inhibited the metabolism of TEST $(P<0.05)$ in a dose-dependent manner. The addition of KET at 1, 5, and $20 \mu \mathrm{mol} / \mathrm{L}$ resulted in 2.9-, 4.5-, and 28.6-fold reductions in the TEST metabolism (Figure 1E), indicating that the in vitro system with HepG2 cells is also appropriate for assessing the metabolic pathway involved in CYP3A4. Also, the metabolic capacity of HepG2 cells was similar to that of the microsome system, and the CYP2D6 and 3A4 activities in HepG2 cells were adjustable.

\section{Modulation of the PPP and metabolic capacity of HepG2 cells}

To evaluate the effects of modulating the PPP on drug metabolism, a typical inhibitor and activator of p53 were used, and their effects on drug metabolism were examined. We found that cyclic PFT-a, a wild-type p53 specific inhibitor ${ }^{[20]}$, downregulated p53 expression at both the mRNA (Figure 2A) and protein (Figure $2 \mathrm{~B}$ ) levels without affecting the CYP expression. Moreover, cyclic PFT-a significantly increased the intracellular NADPH levels and the NADPH/NADP ${ }^{+}$ratio (Figure 2C). Examination of the typical two substrates of CYP2D6 (Figure 2D) and CYP3A4 (Figure 2E) in HepG2 cells showed that the addition of cyclic PFT-a elevated their metabolism. For TEST, its metabolism increased by 1.5-, 2.5-, and 3.4-fold with 3,10 , and $25 \mu \mathrm{mol} / \mathrm{L}$ of cyclic PFT- $\alpha$, respectively, indicating that p53 inhibition increased the efficiency of TEST metabolism.

NSC 66811 is a potential MDM2 inhibitor that disrupts MDM2-p53 interaction and activates p53 function ${ }^{[21]}$. The p53 mRNA levels were up-regulated by NSC 66811 (Figure 2F) without affecting the CYP expression. NSC 66811 decreased the metabolism of DEM (Figure 2G) and TEST (Figure 2H) in a dose-dependent manner. For CYP3A4, the metabolism of TEST was reduced by 1.5-, 2.9-, and 6.8-fold with 3, 10, and 25 $\mu \mathrm{mol} / \mathrm{L}$ of NSC 66811, respectively, indicating that p53 activation decreased the metabolic efficiency through both CYP2D6 and $3 \mathrm{~A} 4$.

To evaluate the effects of directly modulating the PPP on drug metabolism, an inhibitor and activator of the PPP were used to examine their effects on drug metabolism. First, the effects of 6-AN, a G6PD inhibitor ${ }^{[22]}$ and menadione (Mena, a PPP activator ${ }^{[23]}$ ) on G6PD activity in HepG2 cells were examined. The data showed that 6-AN $(15 \mu \mathrm{mol} / \mathrm{L})$ downregulated $(P=0.078)$ G6PD activity, while Mena $(15 \mu \mathrm{mol} / \mathrm{L})$ up-regulated $(P=0.147)$ it (Figure S2). Moreover, 6-AN significantly down-regulated both the mRNA (Figure 3A) and protein (Figure 3B) levels of G6PD. Measurements of the metabolic rates of DEM and TEST in HepG2 cells showed that the addition of 6-AN attenuated their metabolism (Figure 3C), indicating that the direct inhibition of G6PD activity and expression decreased the metabolic efficiency through CYP2D6 and CYP3A4. When the PPP activity was stimulated in the presence of Mena, the metabolic rates of DEM and TEST were significantly increased. The addition of Mena at 1,5 , and $15 \mu \mathrm{mol} / \mathrm{L}$ resulted in a 2.2-, 3.1-, 4.1-fold and 1.4-, 1.7-, and 2.1-fold increases, respectively, in the metabolic rates of DEM and TEST (Figure 3D). This suggested that direct modulation of the PPP significantly altered the metabolic capacity of HepG2 cells.

\section{Discussion}

\section{The effect of modulation of the PPP on drug metabolism}

Although pharmacogenetics play an important role in the therapeutic failure and unwanted side effects of a drug ${ }^{[24]}$, they only partially contribute to the individual drug metabolism variance. Apart from CYP polymorphisms, other factors that significantly contribute to the individual variance of drug metabolism remain largely unknown. Bridging endogenous metabolism and xenobiotic metabolism, the PPP is involved in the activity of G6PD and generation of NADPH, which plays a key role in drug metabolism. The PPP is a vital contributor to glycometabolism by providing ribose-5-phosphate for nucleic acid synthesis and reducing the energy to cells by maintaining the NADPH levels ${ }^{[25]}$.

G6PD is a key rate-limiting enzyme in the PPP, whose activity can be regulated by $\mathrm{p} 53^{[13]}$ and TAp73 ${ }^{[26,27]}$. G6PD converts glucose-6-phosphate into 6-phosphoglucono-deltalactone and simultaneously produces NADPH. The NADPH in turn maintains the glutathione levels in these cells, protecting against oxidative damage. Our data clearly showed that the drug metabolism could not only be regulated directly by a G6PD inhibitor (6-AN) and a PPP activity stimulator (Mena), but also indirectly regulated by a p53 inhibitor (cyclic PFTa) and activator (NSC 66811). These results suggested that both p53 and G6PD play important roles in drug metabolism, which is important for the generation of NADPH in HepG2 cells (Figure 4). To establish the relationship between the level of NADPH and drug metabolism capacity, additional studies will be designed and performed in the near future.

It has been recognized for some time that individual parameters, such as gender, age, body weight, and nutrition as well as lifestyle factors, such as alcohol, tobacco, physical exercise, and food preference, contribute to individual variations in drug metabolism ${ }^{[28-31]}$. However, it is unknown how these external factors (epi-factors) affect the intrinsic function of drug metabolism. Although the individual parameters are thought to contribute to the body's biological metabolism, the variation in the NADPH levels and G6PD activity involved in the crucial glycolysis/PPP inevitably affects the catalytic activity of CYPs through electron and hydrogen transmission. It was further suggested that PPP activity might affect and reflect the drug metabolism. As a comprehensive indicator of drug metabolism, an individual metabolic baseline may play a 
A

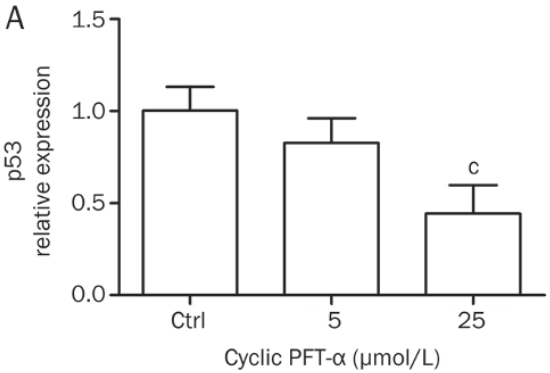

C
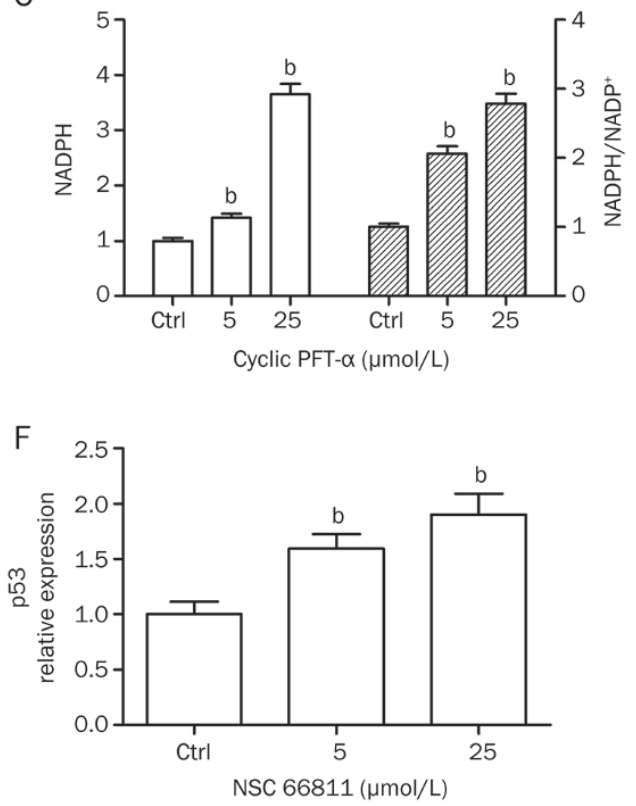

B

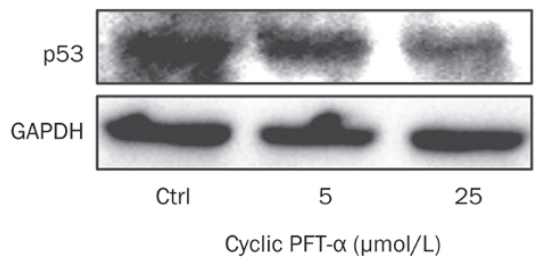

D
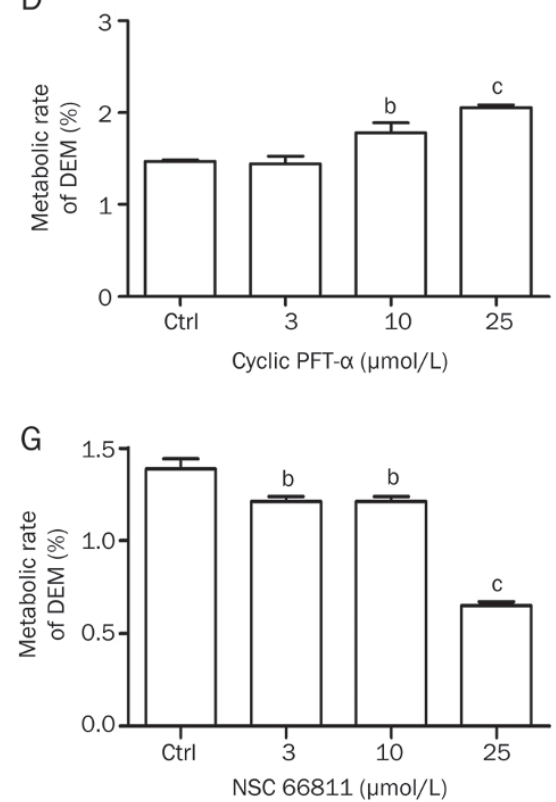

E

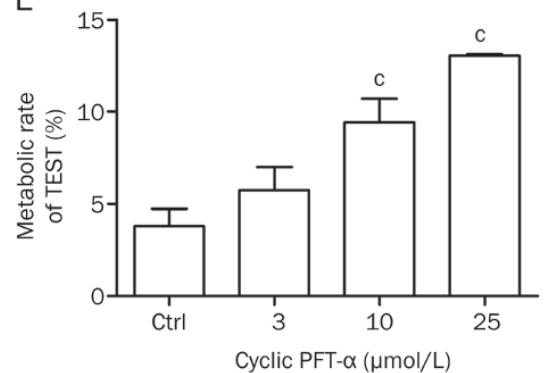

$\mathrm{H}$

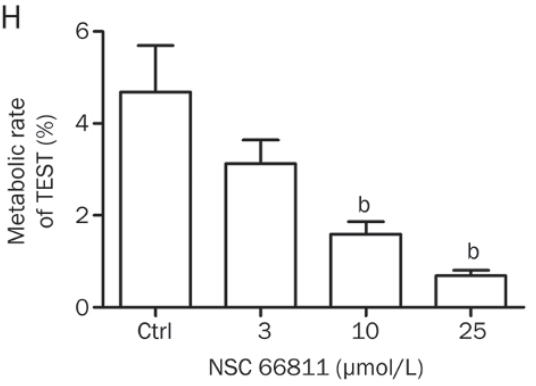

Figure 2. Effects of a p53 inhibitor and activator on the metabolic capacity of HepG2 cells. (A) Inhibitory effect of cyclic PFT- $\alpha$ on p53 mRNA expression in HepG2 cells. Cells were cultured for $24 \mathrm{~h}$ in the absence (Ctrl) or presence of cyclic PFT- $\alpha$ ( 5 or $25 \mu \mathrm{mol} / \mathrm{L}$ ). The results are presented as the relative mRNA expression levels compared to $\beta$-actin. (B) Inhibition of cyclic PFT- $\alpha$ on the expression of p53 in HepG2 cells at the protein level (24 h). (C) The intracellular NADPH levels and the NADPH/NADP ${ }^{+}$ratio in HepG2 cells were influenced by cyclic PFT- $\alpha$ in a dose-dependent manner. NADPH, NADP ${ }^{+}$and their ratio were determined with an NADP/NADPH Quantitation Colorimetric Kit (Biovision, USA) after $24 \mathrm{~h}$ treatment with cyclic PFT- $\alpha$. (D) Promotion of the DEM $(1 \mu \mathrm{mol} / \mathrm{L})$ metabolic rate by cyclic PFT- $\alpha$ in HepG2 cells. Cells were incubated for $24 \mathrm{~h}$ in either the presence or absence of cyclic PFT- $\alpha$ (3, 10, and $25 \mu \mathrm{mol} / \mathrm{L})$. (E) Promotion of the TEST (10 $\mu \mathrm{mol} / \mathrm{L})$ metabolic rate by cyclic PFT- $\alpha$ in HepG2 cells (24 h). (F) Effect of NSC 66811 on the p53 mRNA expression in HepG2 cells. Cells were treated for $24 \mathrm{~h}$ with NSC 66811 ( 5 and $25 \mu \mathrm{mol} / \mathrm{L})$. (G) Inhibition of the DEM (1 $\mu \mathrm{mol} / \mathrm{L})$ metabolic rate by NSC 66811 in HepG2 cells. Cells were incubated for $24 \mathrm{~h}$ in either the presence or absence of NSC 66811 (3, 10, and $25 \mu \mathrm{mol} / \mathrm{L})$. (H) Inhibition of the TEST $(10 \mu \mathrm{mol} / \mathrm{L})$ metabolic rate by NSC 66811 in HepG2 cells $(24 \mathrm{~h}) .{ }^{\mathrm{b}} \mathrm{P}<0.05,{ }^{\mathrm{c}} P<0.01 \mathrm{vs}$ Ctrl.

key role in interpreting the individual variance in drug metabolism.

\section{Drug metabolism in HepG2 cells}

To study the modulation effect of the PPP on drug metabolism, a living system/organism has to be employed. Because it seems unrealistic to perform a clinic study or use an animal model, hepatic cells are the best choice. A pair of hepatic cell lines, the cancerous HepG2 and normal L02 cells, were used to study the expression and function of primary CYPs. We observed that the CYP1A2, 2C9, 2C19, 2D6, and 3A4 mRNA expression levels in HepG2 cells were higher than those in L02 cells, and the metabolism of typical substrates for 2D6 and 3A4, DEM and TEST, respectively, in HepG2 cells was also higher than in L02 cells. The DEM and TEST metabolic rates could be markedly reduced by their corresponding specific inhibitors, KET and QND. These results suggested that the metabolic capacity of cancerous HepG2 cells is well preserved and the activity of CYP2D6 and 3A4 is sufficient for this study, even though it was lower than in primary hepatic cells. The easy accessibility, high reproducibility, self-generation, and stable metabolism of drugs in the HepG2 cell line make it an attractive alternative metabolic system for the widely used in vitro microsome system.

\section{Drug metabolism in cancer cells}

For many years, researchers have paid little attention to the metabolic activity of cancer cells, although the expression of 
A
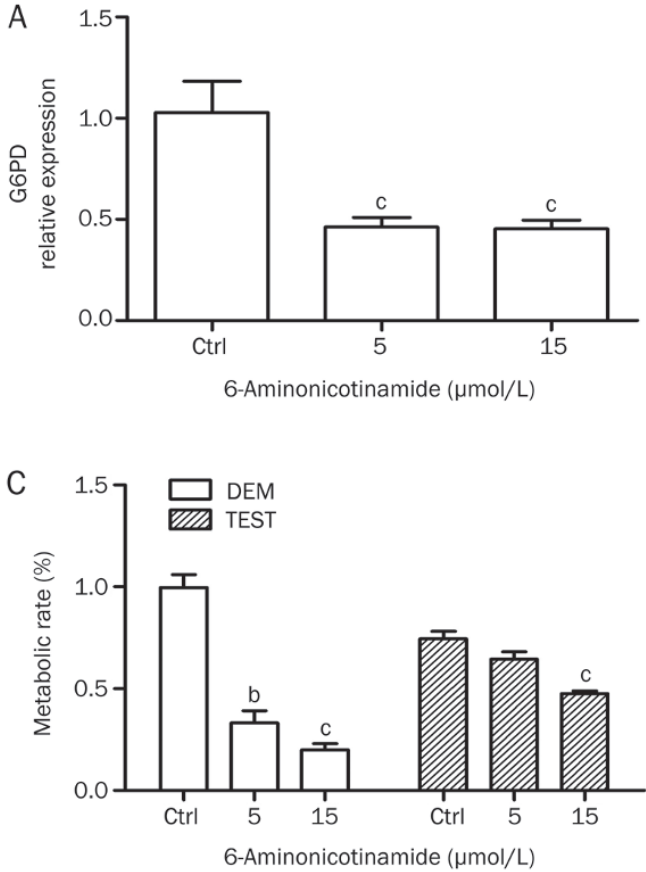

B
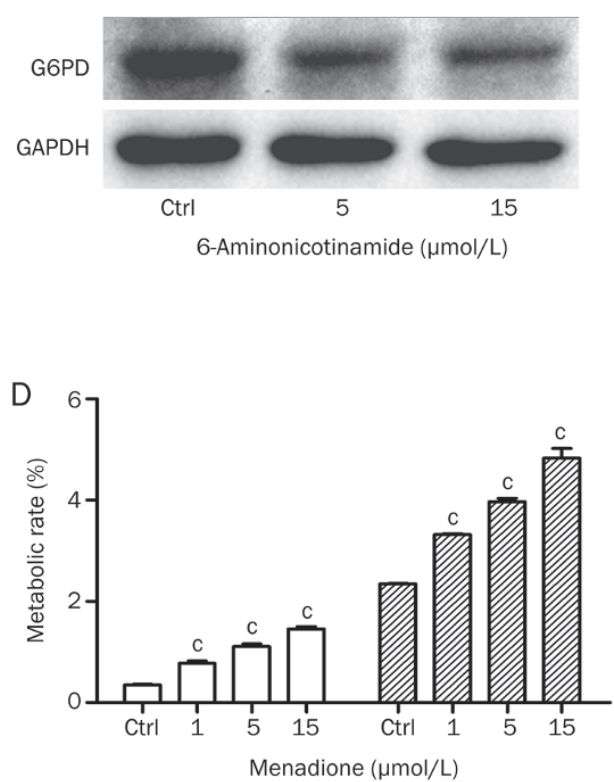

Figure 3. Effect of the PPP modulation on the metabolic capacity of HepG2 cells. (A) Effect of 6-AN on the G6PD mRNA expression levels in HepG2 cells $(24 \mathrm{~h})$. The results are presented as the mRNA expression levels relative to $\beta$-actin. (B) 6 -AN inhibited the G6PD expression in HepG2 cells at the protein level. Cells were cultured for $24 \mathrm{~h}$ in either the absence (Ctr) or presence of 6 -AN ( 5 and $15 \mu \mathrm{mol} / \mathrm{L}$ ). (C) Effect of 6-AN on the metabolic rates of DEM $(1 \mu \mathrm{mol} / \mathrm{L})$ and TEST $(10 \mu \mathrm{mol} / \mathrm{L})$ in HepG2 cells. Cells were incubated for $24 \mathrm{~h}$ in either the presence or absence of $6-\mathrm{AN}(5 \mathrm{and} 10 \mu \mathrm{mol} / \mathrm{L})$. (D) Effect of menadione on the metabolic rates of DEM $(1 \mu \mathrm{mol} / \mathrm{L})$ and TEST $(10 \mu \mathrm{mol} / \mathrm{L})$ in HepG2 cells. Cells were incubated for $24 \mathrm{~h}$ in either the presence or absence of menadione $(1,5$, and $15 \mu \mathrm{mol} / \mathrm{L}) .{ }^{\mathrm{b}} \mathrm{P}<0.05,{ }^{\mathrm{c}} P<0.01 \mathrm{vs}$ Ctrl.

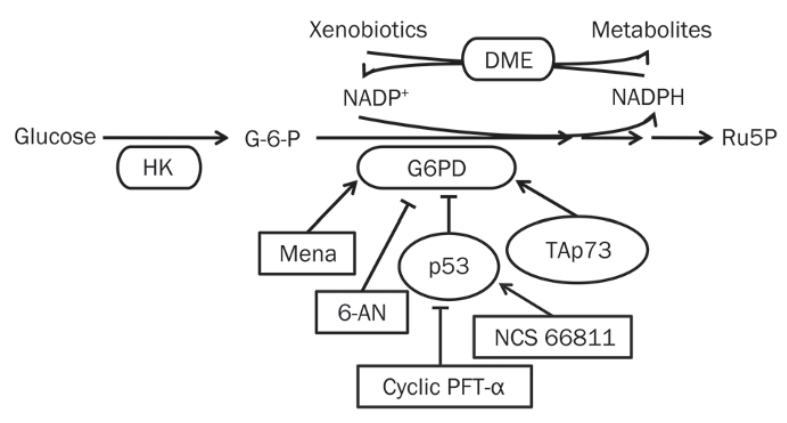

Figure 4. Modulation of drug metabolic activity by PPP and p53 regulators. Activation of p53 by NSC 66811 and inhibition of G6PD by 6-AN decreased both the PPP flux and drug metabolic rates, whereas inhibition of $p 53$ by cyclic PFT- $\alpha$ and stimulation of the PPP by menadione have the opposite effect. Furthermore, TAp73 increased the PPP flux and directed glucose to the production of NADPH by stimulating G6PD. HK, hexokinase; G-6-P, glucose-6-phosphate; G6PD, glucose-6-phosphate dehydrogenase; TAp73, a structural homologue of the pre-eminent p53; Mena, menadione; 6-AN, 6-aminonicotinamide; cyclic PFT- $\alpha$, cyclic pifithrin- $\alpha$ hydrobromide; DME, drug metabolizing enzyme; Ru5P, ribulose5-phosphate.

various CYPs in various tumor tissues has been examined. As a result, scientists have little knowledge on the function of CYPs and specific metabolic pattern of drugs in tumor cells. Because there is a lack of understanding of drug metabolism in tumor cells, no previous studies have elucidated the metabolic differences between cancer cells and healthy tissue. In fact, the metabolic rate of a drug in tumor tissue greatly influences its efficacy, providing an anti-tumor effect ${ }^{[2,33]}$. For the prodrug of an antitumor agent, efficient metabolism can improve its exposure in tumors and vice versa. However, rapid and efficient metabolism can also reduce the exposure of a target drug, which possesses an anti-tumor effect and whose metabolites have few anti-tumor effects and vice versa ${ }^{[34]}$. Understanding the metabolism of a drug in tumor cells will greatly facilitate our assessment of the drug exposure in tumor cells and promote an appropriate design for an anti-tumor agent, and pro-drug, that takes advantage of the metabolic capacity of cancer cells.

Therefore, the metabolism of a drug in cancer cells is of great interest for scientists interested in designing anti-tumor drugs and PK-PD study. Previous studies have shown that the expression levels of many CYP450 isoforms and UDPglucuronosyltransferases (UGTs), glutathione-S-transferases (GSTs), sulfotransferase (SULTs) and sulfatase (SULFs) in hepatoma carcinoma, breast cancer and lung cancer tissues were different from their corresponding normal tissues ${ }^{[17,35-37]}$. The intracellular NADPH levels ${ }^{[38-40]}$ were also different in cancer samples. In accordance with our results, one previous study reported that there are intact phase I and II enzymes, such as CYP1A1, 1A2, 2B, 2C, 3A, 2E1, flavin-containing monooxygenase, $\mathrm{NAD}(\mathrm{P}) \mathrm{H}$ :quinone oxidoreductase, UGTs, GSTs, 
and SULTs in HepG2 cells ${ }^{[41,42]}$. However, relative to human primary hepatocytes, most CYPs showed weak activity and lower mRNA levels ${ }^{[43]}$. As one of the most important enzymes for prodrugs, carboxylesterase also plays a key role in activating prodrugs. Unfortunately, little is known about the function and activity of these enzymes, and future studies should address this.

In summary, we examined the metabolic activity of human hepatoma HepG2 cells and the effect of the PPP modulation on drug metabolism. The data showed that both the expression and metabolic activity of CYP3A4 and CYP2D6 were higher in HepG2 cells than in L02 cells. The metabolism of two typical substrates for CYP3A4 and CYP2D6, (testosterone and dextromethorphan, respectively) was markedly decreased by their corresponding specific inhibitors, KET and QND, indicating that the HepG2 cell line is an alternative metabolic system for the in vitro microsome system. Moreover, in HepG2 cells, drug metabolism could not only be regulated directly by a G6PD inhibitor and PPP activator but also indirectly by modulating p53. These results further suggest that PPP activity might affect drug metabolism, although more studies are needed to confirm the hypothesis. As a comprehensive indicator of drug metabolism, the individual metabolic baseline may play a key role in interpreting individual drug metabolism variances.

\section{Abbreviations}

CYP, cytochrome P450; DEM, dextromethorphan; DEX, dextrorphan; G6PD, glucose-6-phosphate dehydrogenase; GST, glutathione-S-transferase; KET, ketoconazole; $6 \beta-\mathrm{OH}-\mathrm{TEST}$, testosterone-6 $\beta$-hydroxylation; cyclic PFT- $\alpha$, cyclic pifithrin- $\alpha$ hydrobromide; PPP, pentose phosphate pathway; QND, quinidine; TEST, testosterone; UGT, UDP-glucuronosyltransferase.

\section{Acknowledgements}

This study was financially supported by the National Natural Science Foundation of China (No 81072692, 81373481), the Natural Science Foundation of Jiangsu Province (No BK2012762), the Project for Jiangsu Province Key Lab of Drug Metabolism and Pharmacokinetics (No BM2012012), and the Fundamental Research Funds for the Central Universities (№ YD2014SK0002).

\section{Author contribution}

Ji-ye AA, Wen-jing XIAO, and Guang-ji WANG designed the research; Wen-jing XIAO and Ji-ye AA analyzed the data and wrote the manuscript; and Wen-jing XIAO, Ting MA, Chun GE, Wen-juan XIA, Yong MAO, Run-bin SUN, and Xiao-yi YU performed the experiments.

\section{Supplementary information}

Supplementary figures are available on the Acta Pharmacologica Sinica website.

\section{References}

1 Wang L, McLeod HL, Weinshilboum RM. Genomics and drug response.
N Engl J Med 2011; 364: 1144-53.

2 Ingelman-Sundberg M, Sim SC, Gomez A, Rodriguez-Antona C. Influence of cytochrome P450 polymorphisms on drug therapies: pharmacogenetic, pharmacoepigenetic and clinical aspects. Pharmacol Ther 2007; 116: 496-526.

3 Clayton T, Lindon J, Cloarec O, Antti H, Charuel C, Hanton G, et al. Pharmaco-metabonomic phenotyping and personalized drug treatment. Nature 2006; 440: 1073-7.

4 Backshall A, Sharma R, Clarke SJ, Keun HC. Pharmacometabonomic profiling as a predictor of toxicity in patients with inoperable colorectal cancer treated with capecitabine. Clin Cancer Res 2011; 17: 301928.

5 Phapale PB, Kim SD, Lee HW, Lim M, Kale DD, Kim YL, et al. An integrative approach for identifying a metabolic phenotype predictive of individualized pharmacokinetics of tacrolimus. Clin Pharmacol Ther 2010; 87: 426-36.

6 Gao J, Ding XS, Zhang YM, Dai DZ, Liu M, Zhang C, et al. Hypoxia/ oxidative stress alters the pharmacokinetics of CPU86017-RS through mitochondrial dysfunction and NADPH oxidase activation. Acta Pharmacol Sin 2013; 34: 1575-84.

7 Wood T. Distribution of the pentose phosphate pathway in living organisms. Cell Biochem Funct 1986; 4: 235-40.

8 Stanton RC. Glucose-6-phosphate dehydrogenase, NADPH, and cell survival. IUBMB Life 2012; 64: 362-9.

9 DeBerardinis RJ, Lum JJ, Hatzivassiliou G, Thompson CB. The biology of cancer: metabolic reprogramming fuels cell growth and proliferation. Cell Metab 2008; 7: 11-20.

10 Jain M, Nilsson R, Sharma S, Madhusudhan N, Kitami T, Souza AL, et al. Metabolite profiling identifies a key role for glycine in rapid cancer cell proliferation. Science 2012; 336: 1040-4.

11 Warburg 0 . On the origin of cancer cells. Science 1956; 123: 30914.

12 Vander Heiden MG, LC Cantley CB. Thompson, Understanding the Warburg effect: the metabolic requirements of cell proliferation. Science 2009; 324: 1029-33.

13 Jiang P, Du W, Wang X, Mancuso A, Gao X, Wu M, et al. p53 regulates biosynthesis through direct inactivation of glucose-6-phosphate dehydrogenase. Nat Cell Biol 2011; 13: 310-6.

14 Li YX, Lin ZB, Tan HR. Wild type p53 increased chemosensitivity of drug-resistant human hepatocellular carcinoma Bel7402/5-FU cells. Acta Pharmacol Sin 2004; 25: 76-82.

15 Lin HR, Wu CC, Wu YH, Hsu CW, Cheng ML, Chiu DT. Proteome-wide dysregulation by glucose-6-phosphate dehydrogenase (G6PD) reveals a novel protective role for G6PD in aflatoxin B(1)-mediated cytotoxicity. J Proteome Res 2013; 12: 3434-48.

16 Ho HY, Cheng ML, Shiao MS, Chiu DT. Characterization of global metabolic responses of glucose-6-phosphate dehydrogenase-deficient hepatoma cells to diamide-induced oxidative stress. Free Radic Biol Med 2013; 54: 71-84.

17 El-Rayes BF, Ali S, Heilbrun LK, Lababidi S, Bouwman D, Visscher D, et al. Cytochrome p450 and glutathione transferase expression in human breast cancer. Clin Cancer Res 2003; 9: 1705-9.

18 Patterson LH, Murray GI. Tumour cytochrome P450 and drug activation. Curr Pharm Des 2002; 8: 1335-47.

19 Bergheim I, Bode C, Parlesak A. Decreased expression of cytochrome P450 protein in non-malignant colonic tissue of patients with colonic adenoma. BMC Gastroenterol 2005; 5: 34.

20 Zuco VF. Zunino, Cyclic pifithrin-alpha sensitizes wild type p53 tumor cells to antimicrotubule agent-induced apoptosis. Neoplasia 2008; 10: 587-96.

21 Shangary S, Wang S. Small-molecule inhibitors of the MDM2-p53 
protein-protein interaction to reactivate p53 function: a novel approach for cancer therapy. Annu Rev Pharmacol Toxicol 2009; 49: 223-41.

22 Carmona A, Freedland RA. Effect of 6-aminonicotinamide on pentose cycle activity in isolated hepatocytes. Int J Biochem 1990; 22: 5959.

23 Smith PF, Alberts DW, Rush GF. Menadione-induced oxidative stress in hepatocytes isolated from fed and fasted rats: the role of NADPHregenerating pathways. Toxicol Appl Pharmacol 1987; 89: 190-201.

24 Meyer UA. Pharmacogenetics and adverse drug reactions. Lancet 2000; 356: 1667-71.

25 Wood T. Physiological functions of the pentose phosphate pathway. Cell Biochem Funct 1986; 4: 241-7.

26 Du W, Jiang P, Mancuso A, Stonestrom A, Brewer MD, Minn AJ, et al. TAp73 enhances the pentose phosphate pathway and supports cell proliferation. Nat Cell Biol 2013; 15: 991-1000.

27 Jiang P, Du W, Yang X. A critical role of glucose-6-phosphate dehydrogenase in TAp73-mediated cell proliferation. Cell Cycle 2013; 12: 3720-6.

28 Paintsil E, Dutschman GE, Hu R, Grill SP, Wang CJ, Lam W, et al. Determinants of individual variation in intracellular accumulation of anti-HIV nucleoside analog metabolites. Antimicrob Agents Chemother 2011; 55: 895-903.

29 Shen H, Zhang W, Abraham C, Cho JH. Age and CD161 expression contribute to inter-individual variation in interleukin-23 response in $\mathrm{CD}^{+}$memory human T cells. PLoS One 2013; 8: e57746.

30 Wikoff WR, Frye RF, Zhu H, Gong Y, Boyle S, Churchill E, et al. Pharmacometabolomics reveals racial differences in response to atenolol treatment. PLoS One 2013; 8: e57639.

31 Liao K, Niu F, Hao HP. Advances on structure-activity relationship of NQ01-targeting antitumor quinones. Chin J Nat Med 2012; 10 : 170-6.

32 Chang TK, Weber GF, Crespi CL, Waxman DJ. Differential activation of cyclophosphamide and ifosphamide by cytochromes P-450 2B and 3A in human liver microsomes. Cancer Res 1993; 53: 5629-37.

33 Tyminski E, Leroy S, Terada K, Finkelstein DM, Hyatt JL, Danks MK, et al. Brain tumor oncolysis with replication-conditional herpes simplex virus type 1 expressing the prodrug-activating genes, CYP2B1 and secreted human intestinal carboxylesterase, in combination with cyclophosphamide and irinotecan. Cancer Res 2005; 65: 6850-7.

34 Marin JJ, Monte MJ, Blazquez AG, Macias RI, Serrano MA, Briz O. The role of reduced intracellular concentrations of active drugs in the lack of response to anticancer chemotherapy. Acta Pharmacol Sin 2014; 35: $1-10$.

35 Kivisto KT, Griese EU, Fritz P, Linder A, Hakkola J, Raunio H, et al. Expression of cytochrome P 4503 A enzymes in human lung: a combined RT-PCR and immunohistochemical analysis of normal tissue and lung tumours. Naunyn Schmiedebergs Arch Pharmacol 1996; 353: 207-12.

36 Martinez V, Kennedy S, Doolan P, Gammell P, Joyce H, Kenny E, et al. Drug metabolism-related genes as potential biomarkers: analysis of expression in normal and tumour breast tissue. Breast Cancer Res Treat 2008; 110: 521-30.

37 el Mouelhi M, Didolkar MS, Elias EG Guengerich FP, Kauffman FC. Hepatic drug-metabolizing enzymes in primary and secondary tumors of human liver. Cancer Res 1987; 47: 460-6.

38 Marshall C, Mamary AJ, Verhoeven AJ, Marshall BE. Pulmonary artery $\mathrm{NADPH}$-oxidase is activated in hypoxic pulmonary vasoconstriction. Am J Respir Cell Mol Biol 1996; 15: 633-44.

39 Ushio-Fukai M, Nakamura Y. Reactive oxygen species and angiogenesis: NADPH oxidase as target for cancer therapy. Cancer Lett 2008; 266: 37-52.

40 Sun Y, St Clair DK, Xu Y, Crooks PA, St Clair WH. A NADPH oxidasedependent redox signaling pathway mediates the selective radiosensitization effect of parthenolide in prostate cancer cells. Cancer Res 2010; 70: 2880-90.

41 Knasmuller SW, Parzefall R, Sanyal S, Ecker C, Schwab, UhI M, et al. Use of metabolically competent human hepatoma cells for the detection of mutagens and antimutagens. Mutat Res 1998; 402: 185-202.

42 Doostdar H, Demoz A, Burke MD, Melvin WT, Grant MH. Variation in drug-metabolizing enzyme activities during the growth of human Hep G2 hepatoma cells. Xenobiotica 1990; 20: 435-41.

43 Donato MT, Lahoz A, Castell JV, Gomez-Lechon MJ. Cell lines: a tool for in vitro drug metabolism studies. Curr Drug Metab 2008; 9: 1-11. 